\title{
Detection and identification of Variola virus in fixed human tissue after prolonged archival storage
}

\author{
Randal J Schoepp ${ }^{1}$, Michelle D Morin ${ }^{1,6}$, Mark J Martinez ${ }^{2}$, David A Kulesh ${ }^{1}$, Lisa Hensley ${ }^{3}$, \\ Thomas W Geisbert ${ }^{3}$, Daniel R Brady ${ }^{4}$ and Peter B Jahrling ${ }^{5}$ \\ ${ }^{1}$ Diagnostic Systems Division, United States Army Medical Research Institute of Infectious Diseases, \\ Frederick, MD, USA; ${ }^{2}$ Pathology Division, United States Army Medical Research Institute of Infectious \\ Diseases, Frederick, MD, USA; ${ }^{3}$ Virology Division, United States Army Medical Research Institute of \\ Infectious Diseases, Frederick, MD, USA; ${ }^{4}$ Indiana University School of Dentistry, Indianapolis, IN, USA; \\ ${ }^{5}$ Headquarters, United States Army Medical Research Institute of Infectious Diseases, Frederick, MD, USA \\ and ${ }^{6}$ GEO-CENTERS, Inc., United States Army Medical Research Institute of Infectious Diseases, Frederick, \\ $M D, U S A$
}

\begin{abstract}
Smallpox disease has been eradicated from the human population since 1979, but is again a concern because of its potential use as an agent of bioterrorism or biowarfare. World Health Organization-sanctioned repositories of infectious Variola virus are known to occur in both Russia and the United States, but many believe other undeclared and unregulated sources of the virus could exist. Thus, validation of improved methods for definitive identification of smallpox virus in diagnostic specimens is urgently needed. In this paper, we describe the discovery of suspected Variola infected human tissue, fixed and preserved for decades in largely unknown solutions, and the use of routine histology, electron microscopy, and ultimately DNA extraction and fluorogenic $5^{\prime}$ nuclease (TaqMan ${ }^{\mathbb{R}}$ ) assays for its identification and confirmation.

Laboratory Investigation (2004) 84, 41-48, advance online publication, 20 November 2003; doi:10.1038/labinvest.3700008
\end{abstract}

Keywords: Variola virus; smallpox; fixed tissue; paraffin-embedded; DNA extraction; TaqMan ${ }^{\circledR}$

Smallpox is a devastating disease with stringent species specificity that is unique to humans. This characteristic enabled the World Health Organization (WHO) global smallpox eradication program to control and ultimately eradicate the disease from the face of the Earth in 1979. The last cases of endemic smallpox disease were reported in 1977, but the virus continues to be a subject of research, discussion, and controversy. ${ }^{1-4}$ Today, infectious Variola virus is known to occur in only two WHOsanctioned collaborative centers, the Centers for Disease Control and Prevention (CDC), Atlanta, USA and the State Research Center of Virology and Biotechnology (Vektor), Novosibirsk, Russia. However, concern remains that undisclosed reference stocks of the virus may exist outside of these two maximum biocontainment laboratories. ${ }^{5}$ Of

Correspondence: RJ Schoepp, Diagnostic Systems Division, 1425 Porter Street, Fort Detrick, Frederick, MD 21702-5011, USA.

E-mail: randal.schoepp@amedd.army.mil.

Received and accepted 16 September 2003; published online 20 November 2003 increasing apprehension is the potential use of Variola as a biological weapon.

Variola virus, the cause of smallpox, is a member of the family Poxviridae, subfamily Chordopoxvirinae, genus Orthopoxvirus. In addition to Variola virus, the genus includes vaccinia (the component of modern day smallpox vaccine), monkeypox, camelpox, cowpox, and other viruses that are antigenically related. ${ }^{6}$ Variola virus is spread by the aerosol route and has an incubation period of 7-17 days. In ordinary-type smallpox, depending on the infecting strain of virus, the severity of the disease can be categorized as Variola minor or Variola major. Variola minor has a low case fatality rate $(1 \%)$ in contrast to the more severe Variola major $(10-30 \%) .^{7}$ Clinically, fever, headache, malaise, severe aching pains, and prostration characterize smallpox disease. Approximately 2-6 days after the initial symptoms, a maculopapular exanthematous rash develops over the face and extremities, which progresses to vesicles and then to pustules. Death from smallpox is the result of an incompletely characterized toxemia, sometimes clearly associated with immune complexes or from 
secondary bacterial infections. Vaccination with certain strains of vaccinia virus provides long-term immunity to Variola infection, and enabled the eventual eradication of smallpox disease.

Today, smallpox is again a concern because of its potential use as an agent of bioterrorism or biowarfare ${ }^{1-4}$ The highly contagious nature of Variola and its relative ease of secondary transmission, that is, person-to-person, as well as by airborne mechanisms, make it a threat for civilian and military organizations, which are ultimately responsible for the protection of their respective populations. While the declared WHO-sanctioned stocks of Variola virus are known to occur in both Russia and the United States, many believe and are increasingly concerned that undeclared and unregulated sources of the virus exist. Virus stocks long forgotten in a freezer or deliberately concealed are suspected to occur around the world. The virus may also persist in the environment, such as in corpses of smallpox victims buried in the Arctic permafrost. ${ }^{3}$ In this paper, we describe the discovery of an intact forearm and hand, presumably from a child, fixed and preserved for decades in largely unknown solutions. The generalized exanthematous disease suggested Variola virus among others, and through the use of routine histology, electron microscopy, and ultimately DNA extraction and fluorogenic $5^{\prime}$ nuclease $\left(\right.$ TaqMan ${ }^{\mathbb{R}}$ ) assays, its detection and identification was confirmed.

\section{Materials and methods}

\section{Diagnostic Specimen}

An intact forearm and hand, presumably from a child, clearly showed generalized exanthematous disease (Figure 1a). The specimen was part of a private collection archived at a Midwestern university, rediscovered in 1999, and provided to the United States Army Medical Research Institute of Infectious Diseases (USAMRIID). The university investigation determined the specimen to be approximately 50 years old. The glass container holding the specimen was labeled 'M243 Smallpox' and when discovered, contained the specimen immersed in an unidentified tissue fixative and/or preservative for an indeterminate amount of time. No clinical history was available. In June 1999, the specimen and surrounding solution were allowed to equilibrate in a large volume of fresh $10 \%$ neutral buffered formalin for 21 days before removal and reimmersion in fresh formalin. In December 2001, multiple tissue specimens were collected from the original specimen for routine histology and electron microscopy.

Numerous, discreet, umbilicated pock lesions were noted along all sides of the forearm, and many intact raised lesions, presumably vesicles or pustules, were present on all heavily keratinized surfaces of the hand and digits. Areas of confluent

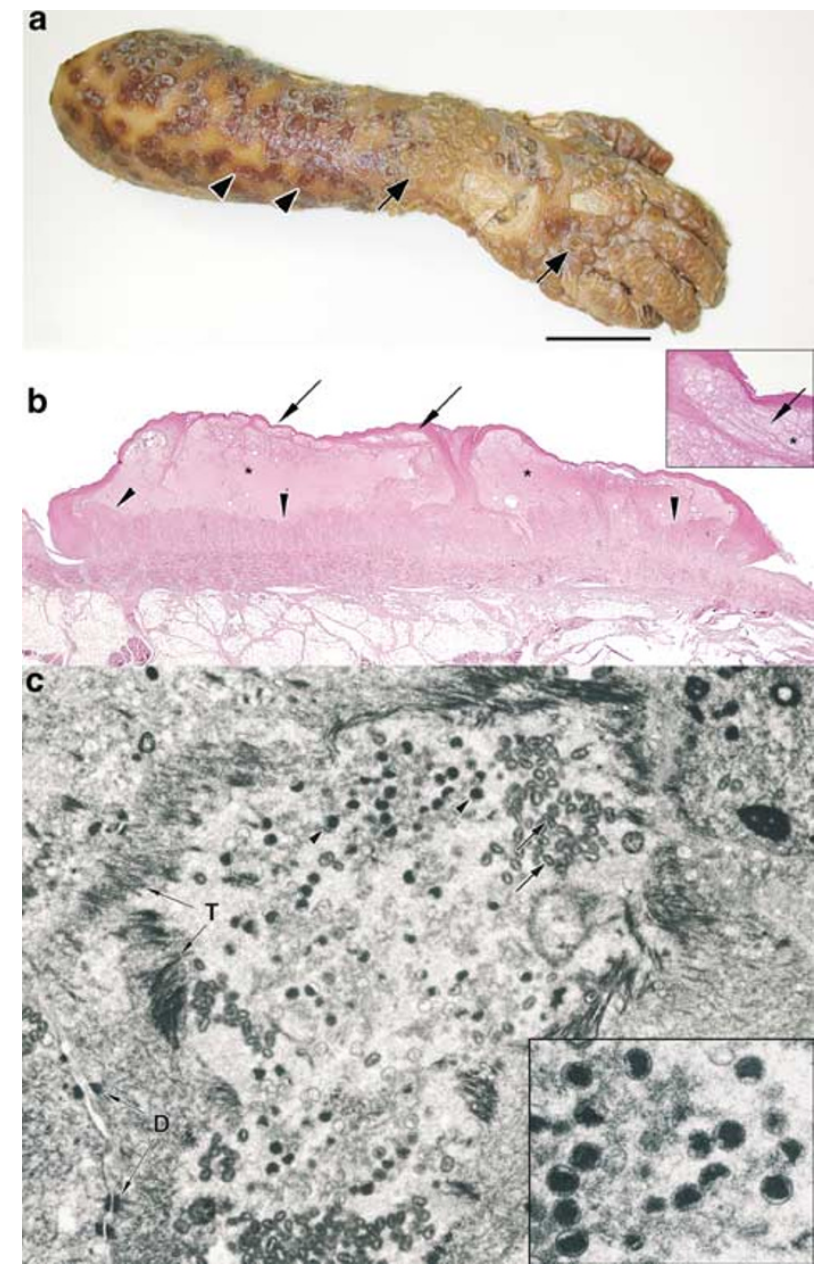

Figure 1 Gross and microscopic images of a human forearm and hand, presumably from a child. (a) All sides of the specimen are similarly affected with discrete and confluent lesions, representing $95 \%$ involvement. Note that the exanthem consist of raised or umbilicated lesions compatible with vesicles or pustules (arrows) primarily around the wrist and on all surfaces of the hand and digits. Crusted or excoriated lesions (arrowheads) predominate the lightly keratinized forearm. Upon receipt of the specimen, it was noted that some lesions had already been collected. $\mathrm{Bar}=5 \mathrm{~cm}$. (b) Macroscopic image of smallpox virus infected skin from the palmar surface of the specimen in the previous figure. Note that the section has lost its thick stratum corneum covering, giving the lesion a pseudoexophytic appearance. The floor of the vesicle (arrowheads) is formed by the remaining stratum germinativum. The vesicle is subdivided, often in a reticular pattern, by remaining strands and septa of intact epidermis that demarcate microvesicles of varied size (arrows); and is filled with proteinaceous material admixed with inflammatory cells, and cellular debris (asterisk) (hematoxylin-eosin, original magnification $\times 1$ ). Higher magnification inset illustrates reticular pattern of microvesicles (hematoxylin-eosin, original magnification $\times 10$ ). (c) Transmission electron micrograph of smallpox virus infected keratinocyte from the palmar surface of the specimen in (a). Although preservation is not optimal, many immature (arrowheads) and mature (long arrows) intracellular virions are readily evident in these rounded epidermal cells. Also note intercellular edema and loss of desmosome attachment; $D$, desmosomes; $T$, tonofilaments; inset, higher magnification of immature intracellular virions; (original magnification $\times 3,500$ ). 
lesions were noted on the wrist. Maceration of the stratum corneum was extensive, and variably sized sheets of stratum corneum separated from underlying, intact epidermal layers. By and large, the most morphologically intact specimens were collected from the heavily keratinized surface of the palm, and these lesions were ultimately chosen for this study.

\section{Histopathology}

Tissue specimens were routinely processed in an automatic tissue processor, embedded in paraffin blocks, sectioned at $5-6 \mu \mathrm{m}$ on a standard rotary microtome, and mounted on glass microscope slides for automated staining with hematoxylin-eosin in a Sakura DRS 601 Slide Stainer (Sakura Finetek USA, Inc., Torrence, CA, USA).

\section{Electron Microscopy}

Tissue specimens were diced into $1-\mathrm{mm}^{3}$ blocks, postfixed in osmium tetroxide, dehydrated in graded steps of ethanol, and flat-embedded in Poly Bed 812 (Polysciences, Inc. Warrington, PA, USA). Ultrathin sections were stained with uranyl acetate and lead citrate, and examined with a Philips CM100 (Philips, Mahwah, NJ, USA) transmission electron microscope at $80 \mathrm{kV}$.

\section{DNA Extraction}

For each tissue specimen, $20 \mu \mathrm{m}$ thick sections were cut on a standard rotary microtome using RNase$Z_{a p}{ }^{\circledR}$ (Ambion, Inc., Austin, TX, USA) on all surfaces coming in contact with the sections and nucleic acid extraction was performed immediately. The Paraffin Block RNA Isolation Kit (Ambion, Inc.) was used with a modified protocol. Briefly, tissue sections were deparaffinized with three washes in Xyless II (Val Tech Diagnostics, Brackenridge, PA, USA), a xylene substitute, followed by three washes in $100 \%$ ethanol, and air-dried for $5 \mathrm{~min}$ at room temperature. The tissue was incubated with proteinase $\mathrm{K}$ for $24 \mathrm{~h}$ at $45^{\circ} \mathrm{C}$ in a thermomixer (Eppendorf, New York, NY, USA) set to shake at $1400 \mathrm{rpm}$. After addition of the guanidine-based lysis buffer, DNA

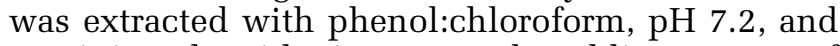
precipitated with isopropanol, adding $10 \mu \mathrm{g}$ of glycogen as a co-precipitant. DNA was pelleted, washed in $70 \%$ ethanol, and air-dried for $15 \mathrm{~min}$ at room temperature. DNA pellets were resuspended in $100 \mu \mathrm{l}$ of $10 \mathrm{mM}$ Tris-1 mM EDTA buffer, $\mathrm{pH} 8.0$ and incubated for $10 \mathrm{~min}$ at $70^{\circ} \mathrm{C}$ to demodify the extracted DNA. ${ }^{8}$

\section{Fluorogenic $5^{\prime}$ Nuclease (TaqMan ${ }^{\circledR}$ ) Assays}

The Orthopox species (spp.) Hemagglutinin (HA) $\operatorname{TaqMan}^{\circledR}$ assay was designed as follows: the forward primer (OPSP-F89) was 5'-GAT GAT GCA ACT CTA TCA TGT A-3'. The reverse primer (OPSPR219) was 5'-GTA TAA TTA TCA AAA TAC AAG ACG TC-3'. The TaqMan ${ }^{\circledR}$ probe (OPSP-p143s) was 6'FAM-AGT GCT TGG TAT AAG GAG CCC AAT TCTAMRA. The Variola-specific HA TaqMan ${ }^{\circledR}$ assay was previously described and was designed as follows: ${ }^{9}$ the forward primer (OPXJ7R3U) was $5^{\prime}$ TCA TCT GGA GAA TCC ACA ACA $-3^{\prime}$ and the reverse primer (OPXJ7R3L) was 5'-CAT CAT TGG CGG TTG ATT TA-3'. The TaqMan $^{\circledR}$ probe (VARJ7R3P) was 6'FAM-CAA GAC GTC GGG ACC AAT TAC TAA TA-TAMRA. The final concentration of the components of the reaction buffer for both assays was: $50 \mathrm{mM}$ Tris ( $\mathrm{pH}$ 8.3), $250 \mu \mathrm{g} / \mathrm{ml} \mathrm{BSA}$ $0.8 \mathrm{U} /$ reaction of Platinum Taq (Invitrogen, Carlsbad, CA, USA). The Orthopox spp. assay used $5 \mathrm{mM}$ $\mathrm{MgCl}_{2}$ while the Variola-specific assay used $7 \mathrm{mM}$ $\mathrm{MgCl}_{2}$. For the Orthopox spp. assay, the final concentration of the primers was $500 \mathrm{nM}$ each. The final concentration of the probe was $100 \mathrm{nM}$ (PE Biosystems, Foster City, CA, USA). For the Variolaspecific assay, the final concentration of the primers was $400 \mathrm{nM}$ each and the probe was $120 \mathrm{nM}$ (PE Biosystems). Both assays were run on the Idaho Technology Ruggedized Advanced Pathogen Detection Device (RAPID) Model 7200 (Idaho Technology, Salt Lake City, UT, USA). The RAPID is a rapid aircycling thermocycler that integrates LightCycler ${ }^{\circledR}$ (Idaho Technology) instrument technology into a portable, impact resistant machine. The cycling conditions for both assays were $2 \mathrm{~min}$ at $95^{\circ} \mathrm{C}$ followed by 45 cycles of $95^{\circ} \mathrm{C}$ for $1 \mathrm{~s}, 60^{\circ} \mathrm{C}$ for $20 \mathrm{~s}$. All assays were read in Channel $1(\mathrm{~F} 1)$ at a gain setting of 16. A fluorescence reading was taken at the end of each $60^{\circ} \mathrm{C}$ step. Each reaction was analyzed by the RAPID software using the LCDA (LightCycler Data Analysis, version 3.1) and the Detector (version 2.0.7) programs. The amplicon size for the Orthopox spp. assay was $131 \mathrm{bp}$ and for the Variola-specific assay was $140 \mathrm{bp}$.

\section{DNA Sequencing}

The amplicon produced in the Variola-specific TaqMan ${ }^{\mathbb{R}}$ assay was sequenced to confirm Variola virus identity. Polymerase chain reactions (PCRs) were prepared as described above except the TaqMan ${ }^{\circledR}$ probes were eliminated and the Variola amplicon was used as PCR DNA templates. To avoid contamination, pre-PCR and post-PCR sample manipulations were completely separated. All PCRs were prepared in a laboratory where no orthopoxviruses had been used. Amplicons were added in a separate laboratory where no orthopoxviruses had been used. Reactions were set up separately in a laminar flow, Class II biological safety hood that was decontaminated and ultraviolet light sterilized between reactions. Replicates of each reaction were pooled and $5 \mu \mathrm{l}$ was electrophoresed on a $4 \%$ TBE 
agarose gel to verify a product of the correct size. The PCR product was purified using the QIAquick PCR Purification Kit (Qiagen, Inc., Valencia, CA, USA) and was sequenced using the PRISM Ready Reaction DyeOxy Terminator Cycle Sequencing Kit (Applied Biosystems Division, Perkin-Elmer Corporation, Foster City, CA, USA). Each nucleotide was determined by sequencing both strands with an ABI Model 377 Automated DNA Sequencer (Applied Biosystems Division, Perkin-Elmer Corporation). Sequence was edited, aligned, and analyzed using the Inherit software package (Applied Biosystems Division, Perkin-Elmer Corporation). The resulting consensus sequence was aligned with known orthopoxvirus HA sequences in GenBank using OMIGA 2.0 (Oxford Molecular, San Diego, CA, USA).

\section{Sequence Analysis and Phylogenies}

The nucleotide sequence of the amplicons produced in the Variola-specific HA TaqMan ${ }^{\circledR}$ assay was compared to the homologous regions of various orthopoxviruses (Table 1). Sequences for the homologous regions of the orthopoxviruses were obtained from GenBank (accession numbers noted in Table 1). Phylogenetic analyses were performed using the Phylogenetic Analysis Using Parsimony (PAUP) program, with equal character weights, nearestneighbor branch-swapping, and a heuristic search for the most parsimonious tree. ${ }^{10}$ The reliability of the inferred tree was estimated using the bootstrap method, with 1000 replications. ${ }^{11}$

\section{Results}

\section{Pathology}

Although only presented with an intact forearm and hand, the pattern of the exanthematous rash noted on this specimen was compatible with the centrifugal pattern of distribution seen in smallpox (Figure 1a). In natural cases of Variola major, the centrifugal distribution affects the face, limbs, hands, and feet, earlier and more extensively than the trunk. Specimen lesions were both discrete and confluent, and representative lesions from all areas of the forearm and hand were examined microscopically. The lesions best suited for routine hematoxylin-eosin staining and the retention of morphology were collected from the palm, and palmar aspects of the hand and wrist. Hematoxylin-eosin staining characteristics in these specimens were suboptimal, presumably resulting from the age of the specimen and the unknown fixation and/or preservative solutions used. Typical morphologic features consistent with a smallpox virus-induced cutaneous pock lesion were noted in the tissue sections examined (Figure 1b). Microscopically, the raised lesions are vesicles or vesicopustules characterized
Table 1 Orthopoxvirus HA genes compared by sequence analysis to sequence recovered from human tissue presumed to be infected with Variola virus.

\begin{tabular}{|c|c|c|c|}
\hline Virus strain & Location & Year & Accession no. \\
\hline Variola major-SOM & Somalia & 1977 & AF375143 \\
\hline Variola major-SLN & Sierra Leone & 1968 & AF375142 \\
\hline Variola major-NIG & Nigeria & 1961 & AF375138 \\
\hline Variola major-RAT & Pakistan & 1969 & AF375141 \\
\hline Variola major-MAD & India & 1962 & AF375137 \\
\hline Variola major-BOM & India & 1958 & AF375128 \\
\hline Variola major-HAR & Unknown & Unknown & None \\
\hline Variola major-CNG & Dem. Rep. Congo & 1970 & AF375131 \\
\hline Variola major-ABA & Bangladesh & 1974 & AF375125 \\
\hline Variola minor-GAR & Garcia & 1966 & X72086 \\
\hline Variola minor-BUT & United Kingdom & 1952 & AF375129 \\
\hline Vaccinia-WR & Western Reserve & Unknown & M93956 \\
\hline Vaccinia-TT & China & Unknown & M57773 \\
\hline Vaccinia-LST & United Kingdom & Unknown & AF375124 \\
\hline Vaccinia-LEN & Unknown & 1975 & AF375123 \\
\hline Vaccinia-IHDW & Unknown & Unknown & AF375121 \\
\hline Vaccinia-CPN & Denmark & Unknown & AF375122 \\
\hline Vaccinia-81 & India & 1985 & AF375078 \\
\hline Vaccinia-3906 & India & 1985 & AF375077 \\
\hline Monkeypox-CPN & Denmark & 1958 & AF375108 \\
\hline Monkeypox-CNCR & Denmark & Unknown & AF375106 \\
\hline Gerbilpox (Taterapox) & Benin & 1968 & AF375093 \\
\hline Camelpox & Somalia & 1978 & AF375081 \\
\hline Cowpox-58 & Unknown & Unknown & AF375083 \\
\hline Cowpox-BRT & United Kingdom & 1939 & AF375089 \\
\hline Skunkpox & United States & 1978 & AF375120 \\
\hline Ectromelia-MOS & Russia & Unknown & AF375092 \\
\hline Rabbitpox-REV & Netherlands & Unknown & AF375118 \\
\hline Rabbitpox-U23 & Netherlands & Unknown & AF375119 \\
\hline
\end{tabular}

by a roof formed primarily of stratum corneum and occasionally other unidentifiable layers presumably strata lucidum and granulosum. The degeneration of the epidermal cells of the stratum spinosum resulted in intracellular swelling (sometimes referred to as ballooning degeneration), intercellular edema, and ultimately cellular lysis leading to the formation of microvesicles. Microvesicles are often separated by intact, variably thick septa of epidermal cells, which results in a distinct reticular appearance. The microvesicles coalesced multifocally, resulting in the formation of progressively larger vesicles, still protected by the intact cornified layer forming the roof. The cellular debris in the vesicular contents was admixed with macrophages and polymorphonuclear inflammatory cells (neutrophils), and marks the beginning of the transition to a pustule. Vesicles and pustules contained, in addition to cellular and nuclear debris and inflammatory cells, some exfoliated epidermal cells, and proteinaceous material, which was interpreted to be fibrin. The papillary and superficial dermis contained numerous mononuclear and polymorphonuclear inflammatory cells, interpreted as lymphocytes, histiocytes, and neutrophils, which also surrounded vessels, nerves, glands, and extended into the subjacent adipose tissue and overlying epidermis. 


\section{Ultrastructural Morphology}

Although interpretation is somewhat hindered by suboptimal tissue preservation, examination by transmission electron microscopy readily revealed rounded epidermal cells containing coarsely granular viroplasm often closely associated with and seen within incipient viral envelopes. Numerous developing and immature virus particles in various stages of morphogenesis, as well as mature virus particles demonstrating core, lateral bodies, outer membrane, and envelope were evident (Figure 1c). In the thin sections examined, classic intracellular mature virions varied in measurements from approximately $190 \times 320-370 \mathrm{~nm}$. Additionally, edematous intercellular spaces occasionally contained mature virus particles.

\section{Fluorogenic $5^{\prime}$ Nuclease $\left(\right.$ TaqMan $\left.^{\circledR}\right)$ Assays}

The TaqMan ${ }^{\circledR}$ assays for both Orthopox spp. and Variola-specific DNA were run using DNA isolated from the tissue sections listed in Table 2. While the Variola-specific assay only detected smallpox DNA in one of the sections of human arm lesions (21186111), the Orthopox spp. assay detected viral DNA in three human arm lesion sections (211861-09, 11 and -12). Both assays were also tested with five experimentally Variola-infected nonhuman primate (NHP) skin lesion sections. ${ }^{12}$ Results indicated that of the NHP sections, three sections tested positive for both orthopox and Variola DNA (211128-48, -55, and -56), while one sample (211128-60) tested positive for orthopox DNA only. In addition, neither orthopox nor Variola DNA was detected in NHP section 211128-61.
All human arm samples extracted and tested in the TaqMan ${ }^{\circledR}$ assays were reamplified by nested PCR (data not shown). All samples that were positive by the TaqMan ${ }^{\circledR}$ assay were also positive for the nested PCR assay and no new positive samples were identified from experimental samples or negative controls.

\section{DNA Sequencing}

The $139 \mathrm{bp}$ amplicon produced from the Variolaspecific TaqMan ${ }^{\circledR}$ assay was sequenced and compared to related orthopoxviruses (Table 1). When aligned to other Variola virus strains the sequence coincided from base pairs 600 to 738 of the HA gene (data not shown). Phylogenetic analysis using the 139 nucleotide portion of the arm amplicon compared with the HA gene of a variety of orthopoxviruses showed that the arm isolate was most closely related to the Variola HA gene region and more specifically probably the Variola major isolates (Figure 2).

\section{Discussion}

Today, infectious Variola virus is known to exist in only two WHO-sanctioned repositories, the CDC, Atlanta, United States and the State Research Center of Virology and Biotechnology (Vektor), Novosibirsk, Russia. The virus may also occur elsewhere in the world as a result of intentional concealment or unintentional oversight. Although the child's forearm and hand harbored no infectious smallpox virus, having been immersed in fixative for over 50 years, the medical curiosity that once illustrated an

Table 2 TaqMan ${ }^{\circledR}$ analysis of human tissue presumed to be infected with Variola virus and stored in fixative for a prolonged period of time

\begin{tabular}{|c|c|c|c|c|c|}
\hline Sample & Species & Tissue & Agent & Orthopoxvirus assay & Variola assay \\
\hline $990107-25$ & $\mathrm{NHP}^{\mathrm{a}}$ & Liver & Negative & Not detected $^{\mathrm{b}}$ & Not detected \\
\hline 211124-11 & NHP & Liver & Variola & Present & Present \\
\hline $211163-28$ & NHP & Skin & Negative & Not detected & Not detected \\
\hline $211128-48$ & NHP & Skin & Variola & Present & Present \\
\hline $211128-55$ & NHP & Skin & Variola & Present & Present \\
\hline $211128-56$ & NHP & Skin & Variola & Present & Present \\
\hline $211128-60$ & NHP & Skin & Variola & Present & Not detected \\
\hline 211128-61 & NHP & Skin & Variola & Not detected & Not detected \\
\hline 961707 & Human & Liver & Negative & Not detected & Not detected \\
\hline 211861-09 & Human & Skin & Unknown & Present & Not detected \\
\hline 211861-10 & Human & Skin & Unknown & Not detected & Not detected \\
\hline 211861-11 & Human & Skin & Unknown & Present & Present \\
\hline 211861-12 & Human & Skin & Unknown & Present & Not detected \\
\hline
\end{tabular}

${ }^{\mathrm{a}} \mathrm{NHP}=$ nonhuman primate.

RAPID Detector software designations: present = positive; not detected = negative.

Italic entries indicate the experimental samples from the numerous controls. 


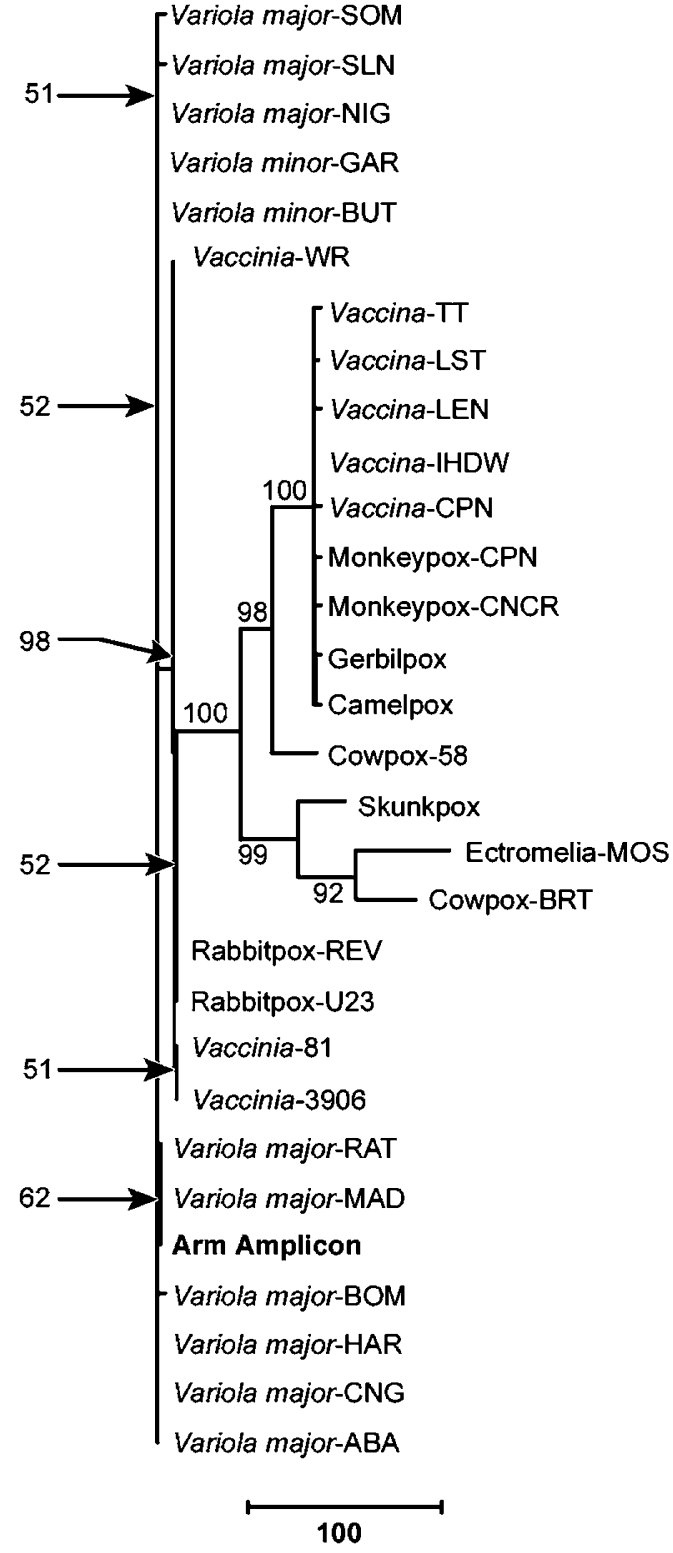

Figure 2 Phylogenetic tree constructed based on a portion of the nucleotide sequence of orthopoxvirus HA genes.

eradicated disease was largely forgotten in time. Its rediscovery afforded a unique and unparalleled opportunity to test our modern, integrated, diagnostic capabilities.

From an anatomic pathology perspective, we have shown that the gross, microscopic, and ultrastructural morphologic changes noted in the exanthematous lesions from this human specimen are consistent with those caused by Variola (smallpox) virus. The distribution of the exanthem on the forearm and hand is compatible with that described by others, and suggests that this distribution would also have been consistent with a centrifugal pattern of distribution if complete postmortem data were available. $^{13}$ Areas of confluent lesions and the histomorphologic features of the palmar lesions are also consistent with smallpox. The ballooning degeneration primarily affecting the stratum spinosum, the epidermal cytolysis, microvesicle and vesicle formation, the reticular pattern in the early vesicle formed by remaining epidermis, and the inflammation present in the subjacent dermis are all consistent with smallpox vesicular/vesiculopustular lesions. The presence of low to moderate numbers of inflammatory cells in the vesicles strongly suggested the beginning of a pustule, which is the next stage in the development of a Variola pock. Other lesions from the forearm appeared crusted, and we believe that the lightly keratinized character of the skin of the forearm facilitated the erosion of relatively fragile vesicles or vesicopustules; or, less likely, and inconsistent with the pathogenesis of smallpox rash, these lesions represent different stages when compared to those present on heavily keratinized surfaces. Morphologically, the differential diagnosis included smallpox, chickenpox (varicella), monkeypox, and other viral or bacterial exanthematous diseases. Attempts to rule in or out smallpox virus initially focused on in situ hybridization and immunohistochemistry using proven protocols, reagents, and controls; however, both techniques when applied to replicate sections from this specimen were unsuccessful (data not shown). Various attempts at antigen retrieval for immunohistochemistry failed to provide immunolabeling. Similarly, an in situ hybridization assay, originally optimized for orthopoxvirus-infected tissues, was unsuccessful. While it is unknown why we were unable to detect viral antigen or nucleic acids by these methods, one could speculate that the extensive cross-linking that occurred from years of fixation rendered the viral epitopes or nucleic acids inaccessible to the respective molecular probes. It is also possible that the amount of virus present was below the level of detection of these assays. However, electron microscopic examination readily revealed typical orthopoxvirus particles illustrating replication, and immature and mature stages. Ultrastructural features consistent with herpesvirus, paramyxovirus, or bacterial infection were not evident, and at this point we were confident that the combined morphologic features indicated a presumptive case of primary smallpox disease.

To add confidence to our presumptive diagnosis, we extracted DNA from tissue sections and tested them for the presence of orthopoxvirus and Variolaspecific viral DNA using fluorogenic $5^{\prime}$ nuclease or TaqMan $^{\circledR}$ assays. Formalin-fixed, paraffin-embedded (FFPE) tissues offered an ideal source of Variola-infected specimens; however, the modifications to the DNA induced by fixation makes viral nucleic acid detection and identification difficult. Formalin fixation of tissues is the most widely used technique for preservation of tissues. Formalin is inexpensive, readily available, preserves cellular morphological characteristics, and is compatible 
with immunohistochemical staining. However, it does have its disadvantages, since it is a progressive fixative that results in excessive cross-linking of proteins over time. This and other DNA modifications are common and result in fragmentation of the DNA, which complicates its downstream uses such as Southern blot hybridization, in situ hybridization, and restriction enzyme digestion. ${ }^{14-16}$ It has also been demonstrated that increased fixation times further decreases the amount of long, intact DNA available. ${ }^{14}$ Generally, after extraction from FFPE tissues, the average DNA fragment length is 1001500 bp. ${ }^{15,17}$ TaqMan $^{\circledR}$ assays are ideally suited for such a situation, where target DNA is fragmented and in low concentration. These PCR-based assays require only small amplicons of $100-150$ base pairs and a specific probe for identification. ${ }^{17}$

Analysis of the $\operatorname{TaqMan}^{\circledR}$ assay results demonstrated that we were able to detect orthopox and Variola viral DNA extracted from FFPE tissue sections; however, the results were highly variable. This variation may have been dependent on several factors. Since the distribution of virus varies among and within tissues, not all tissue sections chosen for extraction will have sufficient virions to generate a detectable level of DNA target. Age of the tissue may also play a role in the variability of the signal. It was more difficult to detect both orthopoxvirus and Variola virus analyte DNA in the 50-year-old specimen of human arm than in the 1-2-year-old specimens of NHP. This signal inconsistency in archived tissue specimens is not unusual. Shibata et $a l^{16}$ detecting human papillomavirus in 40-year-old tissue specimens were not able to consistently demonstrate viral DNA in positive samples each time they were tested. While electron microscopy demonstrated that in some tissues the viral load appeared heavy, DNA extracted for TaqMan ${ }^{\mathbb{R}}$ analysis represented only a $20 \mu \mathrm{m}$ tissue section that may have contained less virus. It is likely that the small amount of viral DNA extracted was significantly fragmented and that the quantity of DNA recovered was at or below the level of detection of our assay.

The Variola-specific assay was only able to detect Variola DNA in a single tissue sample (Table 2, Sample 211861-11). This same sample, when tested with the Orthopox spp. assay, was positive on both occasions. We therefore assumed that concentration of target DNA was at or near the limit of detection of the assay, which is 25 genome equivalents. ${ }^{9}$ Interestingly, when we compared the Variola-specific TaqMan ${ }^{\mathbb{R}}$ probe sequence to our amplicon, we found that there was a single mismatch at HA gene position 631 . This single mismatch would explain the apparent lack of sensitivity of the assay when detecting the strain of Variola infecting this human arm. The Variola-infected NHP tissues used as positive controls were experimentally infected with the Variola major strain India 7124, which was a $100 \%$ match to the TaqMan ${ }^{\circledR}$ probe. A homologous TaqMan ${ }^{\circledR}$ probe would be expected to exhibit higher sensitivity for the Variola DNA extracted from the specimen arm. Unfortunately, there was insufficient sample to repeat these assays with a TaqMan ${ }^{\mathbb{R}}$ probe with identical sequence.

As a final confirmation of Variola virus infection, we amplified the original amplicon from the positive Variola-specific assay and sequenced the product. Obtaining $139 \mathrm{bp}$ of sequence from the HA gene region, we compared it to other orthopoxvirus HA sequences and constructed a phylogenetic tree (Figure 2). The sequence of the arm amplicon was grouped with the Variola major virus sequences. While the sequence compared was too small to provide a definitive identification as a Variola major strain, taken together with the supporting pathology, histopathology, and fluorogenic $5^{\prime}$ nuclease assay results we concluded that the child was definitively infected with Variola virus and in all likelihood a Variola major strain related to Variola-RAT (AF375141) and Variola-MAD (AF375137).

This study provided us a unique opportunity to test Variola virus-infected human tissues using Orthopox spp. and Variola-specific TaqMan ${ }^{\mathbb{R}}$ assays developed for clinical and environmental samples. PCR-based diagnostic assays are rapid and robust techniques for the detection and identification of pathogens. The technique is very sensitive and can tolerate small quantities of poor quality DNA template, thus making it the method of choice when assaying nucleic acids extracted from FFPE tissues.

\section{Acknowledgements}

We thank Jeffery F Brubaker, William J Hurtle, Bonnie M Loveless, Neil M Davis, Steven J Moon, Jeffery B Britton, Thomas Larsen, and Larry K Ostby for their skilled technical assistance Additionally, our thanks to Dr George V Ludwig for his help in the phylogenetic analysis. We also thank Dr Melanie P Ulrich, COL Erik A Henchal, and Katheryn F Kenyon for their review of the manuscript. The US Army Medical Research and Materiel Command, STEP IV.08 Diagnostic Technologies supported this work.

The views expressed in this article are those of the authors and do not reflect the official policy or position of the Department of the Army, the Department of Defense, or the US Government.

\section{References}

1 Joklik WK, Moss B, Fields BN, et al. Why the smallpox virus stocks should not be destroyed. Science 1993;262:1225-1226.

2 Mahy BW, Almond JW, Berns KI, et al. The remaining stocks of smallpox virus should be destroyed. Science 1993;262:1223-1224.

3 Berche P. The threat of smallpox and bioterrorism. Trends Microbiol 2001;9:15-18. 
4 Breman JG, Henderson DA. Diagnosis and management of smallpox. N Engl J Med 2002;346:1300-1308.

5 Henderson DA, Inglesby TV, Bartlett JG, et al. Smallpox as a biological weapon: medical and public health management. Working Group on Civilian Biodefense. JAMA 1999;281:2127-2137.

6 Moss B. Poxviridae: the viruses and their replication, In: Field BN, Knipe DM, Howley PM, Chanock RM, Melnick JL, Monath TP, Roizman B, Straus SE (eds). Fields Virology, 3rd edn. Lippincott-Raven Publishers: Philadelphia, PA, 1996, pp. 2637-2671.

7 Fenner F. Poxviruses, In: Field BN, Knipe DM, Howley PM, Chanock RM, Melnick JL, Monath TP, Roizman B, Straus SE (eds). Fields Virology, 3rd edn. Lippincott-Raven Publishers: Philadelphia, PA, 1996, pp 2673-2702.

8 Masuda N, Ohnishi T, Kawamoto S, et al. Analysis of chemical modification of RNA from formalin-fixed samples and optimization of molecular biology applications for such samples. Nucl Acids Res 1999;27: 4436-4443.

9 Ibrahim MS, Kulesh DA, Saleh SS, et al. Real-time PCR assay to detect smallpox virus. J Clin Microbiol 2003;41:3835-3839.

10 Swofford D. PAUP: Phylogenetic Analysis Using Parimony. Illinois Natural History Survey: Champaign, IL, 1993.
11 Felsenstein J. Confidence limits on phylogenies: an approach using the bootstrap. Evolution 1985;39: 783-791.

12 Jahrling PB. Medical countermeasures against the reemergence of smallpox virus, In: Knobler S, Mahmoud A, Pray L (eds). Biological Threats and Terrorism: Assessing the Science and Response Capabilities. National Academy Press: Washington, DC, 2002, pp 50-53.

13 Fenner F, Henderson DA, Arita I, et al. Smallpox and Its Eradication. World Health Organization, Geneva, 1988.

14 Dubeau L, Chandler LA, Gralow JR, et al. Southern blot analysis of DNA extracted from formalin-fixed pathology specimens. Cancer Res 1986;46:2964-2969.

15 Goelz SE, Hamilton SR, Vogelstein B. Purification of DNA from formaldehyde fixed and paraffin embedded human tissue. Biochem Biophys Res Commun 1985;130:118-126.

16 Shibata D, Martin WJ, Arnheim N. Analysis of DNA sequences in forty-year-old paraffin-embedded thintissue sections: a bridge between molecular biology and classical histology. Cancer Res 1988;48: 4564-4566.

17 Lehmann U, Kreipe H. Real-time PCR analysis of DNA and RNA extracted from formalin-fixed and paraffinembedded biopsies. Methods 2001;25:409-418. 